\title{
SOCIEDADE DO CONSUMO E A COMUNICAÇÃO: UMA ANÁLISE SOBRE O SHOPPING POPULAR
}

\author{
Nayene Cardoso Furmigare \\ Universidade do Oeste Paulista - UNOESTE, Presidente Prudente, SP. E-mail: nayene.furmigare@hotmail.com
}

\begin{abstract}
RESUMO
A sociedade do consumo de Bauman apresenta-se como elemento central na formação da identidade social dos indivíduos. Muito além da satisfação pessoal em consumir, ela passa a ter um peso primordial na construção das personalidades. O estudo contido neste artigo visa analisar os impactos do consumo na sociedade contemporânea, através do estudo de caso do "Camelódromo", atual Shopping Popular. Os objetivos específicos consistem em oferecer uma visão concisa sobre a natureza do consumo e seu impacto desagregador na vida do indivíduo, além de apontar a comunicação mercadológica trabalhada na estratégia de vendas, para induzir o ato do consumo. A metodologia é proveniente das técnicas de observação direta intensiva e entrevista. O método é o estudo de caso "Camelódromo", localizado na cidade de Londrina-PR. A fundamentação teórico-mercadológica é proveniente dos conceitos analisados por Zygmunt Bauman, Jean Baudrillard e Lívia Barbosa. Os resultados permitem afirmar que o consumo cresce acelerado, causando um confronto com a sociedade, principalmente com o próprio comportamento de querer, desejar e ter.

Palavras-chave: Sociedade; Consumo; Comunicação; Transformação; Shopping Popular.
\end{abstract}

\section{CONSUMER SOCIETY AND COMMUNICATION: AN ANALYSIS ON POPULAR SHOPPING}

\begin{abstract}
Bauman's consumer society is central to the formation of individuals' social identity. Far beyond personal satisfaction in consumption, it starts to have a primordial weight in the construction of personalities. The study in this article aims to analyze the impacts of consumption on contemporary society, through the case study of "Camelódromo", currently Shopping Popular. The objectives are to offer a concise view on the nature of consumption and its impact on the individual's life, in addition to pointing to the marketing communication worked on the sales strategy, to induce or execute consumption. The methodology is proven by intensive direct observation and interview techniques. The method is the case study "Camelódromo", located in the city of Londrina-PR. The theoretical-market foundation is proven by the concepts analyzed by Zygmunt Bauman, Jean Baudrillard and Lívia Barbosa. The permitted results indicate that consumption increases rapidly, causing a conflict with society, especially with the very behavior of wanting, desiring and having.
\end{abstract}

Keywords: Society; Consumption; Communication; Transformation; Popular shopping.

\section{INTRODUÇÃO}

O consumo transformou-se na moral do mundo contemporâneo ${ }^{1}$, tornou-se um elemento

\footnotetext{
1 A História Contemporânea, segundo os historiadores, tem seu início marcado pela Revolução Francesa, em 1789. Disponível em: <https://www.infoescola.com/historia/historia-contemporanea/>
} 
central na formação da identidade social, muito além de uma satisfação da necessidade de consumir. Durante um longo período da Revolução Industrial ${ }^{2}$, o desenvolvimento tecnológico espalhou-se provocando grandes transformações: a aparição das indústrias; o advento da formação do capitalismo; a celeridade na produção de mercadorias através das máquinas; fábricas com maior quantidade $e$ aumento na relação de trabalho. A revolução proporcionou uma era de fortalecimento do sistema econômico e capitalista, subsequente na vida dos indivíduos. "[...] o maquinismo abre verdadeiramente uma nova era na exploração e na rentabilidade do trabalho humano e permite a expansão da revolução industrial" (BULGARELLI, 1975, p.51).

Os trabalhadores do campo emigraram para os novos centros industriais, o artesão se inquieta ou desaparece, surgem os profissionais, empresários, engenheiros, técnicos; uma elite burguesa substitui aquela tradicional da terra e o proletariado nasce e luta. Pouco a pouco, todos os setores da vida são atingidos e transformados: trabalho cotidiano, mentalidade, cultura (BULGARELLI, 1975, p.1).

O interesse em estudar os efeitos do consumo na sociedade, com realce no Shopping Popular e a comunicação mercadológica utilizada, surgiu da necessidade de um conhecimento que contribuísse para a população refletir sobre $o$ alto nível de consumo e compreender os fatores que levam ao ato. $O$ problema que dá origem a este estudo é definido pelas seguintes perguntas: até que ponto os valores subjetivos da vida humana podem ser negociados e comercializados como se fossem meros produtos a venda? Porque o individuo tornou-se materialista ao ponto de preocupar-se mais com os bens do que com os seres humanos? Quais os fenômenos associados à comunicação mercadológica que o "Camelódromo" ${ }^{3}$ utiliza para alcançar a

\footnotetext{
${ }^{2}$ A Revolução Industrial é o conjunto de transformações e mudanças que ocorreram na Europa durante os séculos XVIII e XIX, mais precisamente entre os anos de 1760 e 1860. Disponível em: <https://www.meusdicionarios.com.br/revolucao-industrial>.

${ }^{3} \mathrm{O}$ prédio em que se encontra o "Camelódromo" da cidade de
}

sociedade, sistematizando o consumo?

Partimos do pressuposto de que o indivíduo carrega consigo valores materiais e emblemáticos antes mesmo da Revolução Industrial. O consumo tornou-se um elemento central na concepção da identidade pessoal. A construção das personalidades se dá na medida em que essas se encontram imersas e aceitas no universo da sociedade capitalista do consumo.

A comunicação mercadológica passa a existir nas organizações como forma de anunciar os produtos e serviços com intuito comercial. Com isso, houve a necessidade de criar ferramentas de promoção como: promoções de vendas, outdoor, panfletos, campanhas publicitárias, comerciais, sites de relacionamento com o cliente, redes sociais, etc. No "Camelódromo", as ferramentas que ficam em evidência são baseadas no Mix Promocional, Marketing sem Mídia, Neuromarketing ${ }^{4}$, entre outros, pois os consumidores são instigados a comprar a partir de diversos elementos capazes de estimular seus sentidos, são eles: embalagens, ambientes, sons, vitrine, cheiros, contato físico, facilidade na forma de pagamento, espaço, atendimento, abordagem dos vendedores, anúncios, etc. Esses elementos trazem ao público a sensação de prazer e bem-estar, lazer, prestígio e o reconhecimento social. 0 processo de comunicação é evidente na análise e estratégico na forma como são trabalhados os canais e os meios utilizados. Isso permite compreender, checar e expor as práticas de consumo e consumismo.

O objetivo geral deste trabalho é analisar os impactos do consumo na sociedade contemporânea, através do estudo de caso do "Camelódromo", atual Shopping Popular de Londrina-PR. Já os objetivos específicos consistem em oferecer uma visão concisa sobre a natureza do consumo e seu impacto desagregador na vida do indivíduo. Além disso, busca-se apontar as ferramentas mercadológicas trabalhadas na estratégia de vendas para induzir

\footnotetext{
Londrina foi construído em 1950. Os camelôs não tinham um local fixo para realizar o comércio, portanto ocupavam praças, calçadas, ruas e outros locais públicos geralmente com grande circulação de pessoas. Disponível em: <http://hdl.handle.net/11449/183119>.

${ }^{4}$ Neuromarketing não é uma estratégia de marketing, mas sim uma maneira de estudar o comportamento humano através do entendimento do processamento de informações pelo cérebro. É somente a partir dos dados obtidos que são criadas estratégias e táticas mais eficientes para conduzir o marketing digital pelo funil de vendas. Disponível em: https://viverdeblog.com/neuromarketing/\#neuromarketingconceito>.
} 
$\mathrm{o}$ ato do consumo.

A metodologia adotada é o estudo de caso, já que se busca compreender o processo de comunicação dentro do Shopping Popular e as ferramentas mercadológicas. Os procedimentos técnicos adotados foram à observação direta intensiva e entrevista. A abordagem é qualitativa e a pesquisa se classifica como histórica e exploratória, pois busca uma interpretação através da análise dos processos de comunicação trabalhados para atrair seus consumidores.

O artigo está estruturado da seguinte forma: a primeira parte faz uma análise de consumo e vida para o consumo, na qual os indivíduos são impulsionados pelos desejos de constantemente buscarem experiências e de estarem no padrão que a sociedade impõe. Em seguida, tem-se a comunicação mercadológica, ressaltando as ferramentas de difusão trabalhadas para atraírem consumidores, estimulando o consumo, sendo possível, dessa forma, verificar como isso proporciona aumento nas vendas. Posteriormente, seguem-se a metodologia empregada para o desenvolvimento da pesquisa, a apresentação e análise dos dados obtidos na pesquisa. Para concluir, há ainda uma análise histórica do "Camelódromo", desde o surgimento até os dias atuais, fechando com as considerações finais, em que se discute o que foi obtido com o trabalho desenvolvido.

\section{MÉTODOS}

Este estudo conta com uma base teórica de leitura especifica sobre os temas abordados ao longo do artigo. As obras estudadas são: "Sociedade de Consumo" de Jean Baudrillard; "Vidas Para Consumo - Transformação das pessoas em mercadorias" de Zygmunt Bauman e "Sociedade de Consumo" de Lívia Barbosa.

\section{Consumo e vida para o consumo}

Para Barbosa (2010, p.7), sociedade do consumo é um dos inúmeros rótulos utilizados por intelectuais, acadêmicos, jornalistas e profissionais de marketing para se referirem à sociedade contemporânea. Entende-se o ato de consumir como aquele cuja finalidade é a satisfação das "necessidades básicas" e/ou "supérfluas".

O consumo é percebido por um conjunto de práticas que auxilia no desenvolvimento da identidade das pessoas como seres sociais. Conforme Barbosa (2010, p.8-9) aponta:
O termo sociedade de consumo vem frequentemente associado a outros conceitos como sociedade de consumidores, cultura de consumo, cultura de consumidores e consumismo, que são, na maioria das vezes, usados como sinônimos uns dos outros. [...] a escolha da identidade e do estilo de vida não é um ato individual e arbitrário, como alguns autores o interpretam no contexto das sociedades ocidentais contemporâneas.

Para Bauman (2008), existe a transformação dos indivíduos em mercadorias. Ele pondera o propósito dos impactos desta transformação em todas as extensões da existência. $\mathrm{O}$ autor ressalta que os indivíduos são aliciados, instigados ou até mesmo coagidos, levados assim para o ato do consumo.

[...] o destino final de toda mercadoria colocada à venda é ser consumida por compradores. Os compradores desejarão obter mercadorias para consumo se, e apenas se, consumi-las for algo que prometa satisfazer seus desejos. O preço que 0 potencial consumidor em busca de satisfação está preparado para pagar pelas mercadorias em oferta dependerá da credibilidade dessa promessa e da intensidade desses desejos (BAUMAN, 2008, p. 18).

Ainda segundo Bauman (2008), o consumismo tornou-se a intenção das vivências quando a capacidade de 'querer', 'desejar', 'ansiar por', decorre do convívio humano.

Baudrillard (1981) faz uma análise das particularidades da sociedade atual, na qual ele descreve que o consumo permanece presente no cotidiano e enfatiza a seriedade do significado que as mercadorias podem ter para o consumidor, que chega a viver em função dos 
produtos. Ele aponta que as relações atuais estão atreladas ao consumo de modo que: "O consumo surge como modo ativo de relação (não só como objetos, mas ainda com a coletividade e o mundo), como modo de atividade sistemática e de resposta global, que serve de base a todo nosso sistema cultural" (BAUDRILLARD,1981, p.11).

Pode-se observar que o autor aponta a importância do consumo e a influência que tais mercadorias podem ter para os consumidores. Nessa perspectiva, o consumo está relacionado à identidade, ao convívio social, às ideologias e estilos de vida. Barbosa (2010, p.22-23) defende:

Os produtos similares e
"piratas" permitem que os
estilos de vida sejam
construídos es
desconstruídos e lançados
ao mercado e utilizados
por pessoas cujas rendas
certamente não são
compatíveis com o uso de
muitos deles nas suas
respectivas versões
originais. Com a a
popularização a imitação
dos bens de luxo, a
questão nas sociedades de
consumo modernas é
muito mais de
legitimidade e de
conhecimento sobre como
usar do que o que está
sendo usado.

Sendo assim, consumir implica em um mecanismo de inclusão e exclusão social, aceito no contexto igualitário e autoconsciente. Comprar roupa, sapato, brinquedos, objetos pessoais, eletrônicos, relógios, lugares, marcas, lazer, entre outros, estabelece um parâmetro de pertencimento ao mundo da cultura do consumismo. Segundo Barbosa (2010, p.24), “[...] através do consumo 'construímos' identidades, um número maior de vezes ao confirmarmos e ao conhecermo-nos em produtos, objetos e itens da cultura material que são 'a nossa cara'”.

Para Bauman (2008), quanto mais bombardeada de informações a sociedade for, menor é para o indivíduo o poder de assimilar seu envolvimento como consumidor dentro da sua irracionalidade ao comprar tais bens, estimulado pelas emoções consumistas. A ação do consumo estabelece as relações com o poder, de estar inserido no ambiente social.
Baudrillard (2007, p.19) ressalta que as pessoas chegaram ao ponto em que o gasto submerge em aglomeradas áreas do cotidiano "[...] o consumo invade toda a vida, em que todas as atividades se encadeiam do mesmo modo combinatório, em que o canal das satisfações se encontra previamente traçado, hora a hora [...]".

A conservação da economia do país se faz presente a partir de uma consequência do processo do consumo. A sociedade estimulada em adquirir sempre mais e mais, vem a ser responsável pelo giro e aumento da comercialização socioeconômica do país.

É preciso se tornar uma mercadoria para ter a chance razoável de exercer os direitos e cumprir os deveres de consumidores. "O país", assim como os mercados, precisa de mercadorias; um país que entrega aos mercados de consumo o direito de dar a primeira e a última palavra precisa de residentes que já sejam passíveis de uma rápida e barata comodificação (BAUMAN, 2008, p.89).

O aumento do consumo em massa é visto como um fenômeno do capitalismo, um aspecto geral da cultura como um todo. O país precisa movimentar sua economia, assim como os lojistas precisam garantir seus lucros, tornando a participação da sociedade ativa no ato de consumir.

De acordo com Barbosa (2010, p.59) “[...] O consumo é apresentado como baseado em uma visão de mundo essencialmente materialista e em desejos irracionais por mercadorias que levam as pessoas a se preocuparem mais com os bens do que os demais seres humanos [...]".

É interessante enfatizar que os consumidores adquirem mercadorias seguindo uma lógica que permite sinalizar e demarcar relações sociais. É uma forma de comunicar e distinguir seus hábitos e sua identidade.

Barbosa (2010, p.60) ainda ressalta: “[...] O consumo induz as pessoas à imitação, à competição por status como um dos principais modos de relações sociais, ao individualismo, ao consumo conspícuo e a sua exibição em detrimento de outras formas de sociabilidade $[\ldots] "$. 
É pertinente salientar o consumo por impulso e estimulado pela ansiedade ou compulsão. Está ligado aos estímulos de sensações de felicidade e prazer momentâneo.

São casos extremos de compras não planejadas itens comprados de forma espontânea e completamente não premeditada, em resposta a um repentino sentimento de urgência. São compras não racionais, sem avaliação de necessidades e, em geral, realizadas rapidamente. (PARENTE, 2000, p. 129)

Deste modo, o consumo contemporâneo é constituído pela identidade que todos os indivíduos procuram e é exatamente através do ato de consumir que esses descobrem quem são, o que representam, o valor perante a sociedade e o que almejam combater. É uma combinação de sentimento, insegurança, lógica, razão, poder, querer, desejar e todas as outras emoções.

É levantado então o seguinte questionamento: Onde acaba o útil e começa o inútil, entre o consumo e a cidadania? É preciso entender e analisar que o consumo não é apenas o ato de comprar, adquirir ou obter, e sim a sua dimensão funcional e expressiva, na qual podem ser decididos os valores da vida humana e o convívio em sociedade.

\section{Comunicação Mercadológica}

Mediante a compreensão dos conceitos de Kunsch (2003) sobre comunicação mercadológica, entende-se que as empresas querem conquistar seus consumidores e precisam elaborar estratégias para atingir seu público. São ações voltadas para as vendas, que reforçam a imagem das marcas e produtos, e apontam à lucratividade da organização. "[...] esta comunicação é responsável por toda a produção comunicativa em torno dos objetivos mercadológicos, visando à divulgação publicitária dos produtos ou serviços de uma empresa. Encontra-se veiculada diretamente ao marketing de negócios" (KUNSCH, 2003, p. 154).

Gaudêncio Torquato aponta que:

$$
\begin{aligned}
& \text { A comunicação } \\
& \text { mercadológica objetiva } \\
& \text { promove a troca de }
\end{aligned}
$$

produtos e/ou serviços entre produtor e consumidor, [procurando] atender aos objetivos traçados pelo plano de marketing das organizações, cujo escopo fundamental se orienta para a venda de mercadorias destinadas aos consumidores, num determinado espaço de tempo: apoia-se a publicidade comercial, na promoção de vendas e pode, também, utilizar-se, indiretamente, das clássicas atividades da comunicação institucional. (TORQUATO apud KUNSCH, 2003, p. 163).

Para Parente (2002), uma das amplas razões que levam as pessoas ao consumo são as técnicas de venda e alguns fatores que nos entusiasmam no ato da compra:

Os varejistas procuram
estimular a compra não
planejada em suas lojas
mediante recursos de
merchandising e
desenvolvendo uma
atmosfera aconchegante e
estimulante. Para isso,
utilizam cores, iluminação,
música, fragrâncias, que
criam um sentimento
alegre e de bem-estar,
além de técnicas de
merchandising e
exposições de produtos
que estimulem o interesse
e a motivação de compra
dos consumidores.
(PARENTE, 2002, p. 129).

O autor destaca que quanto mais familiarizados com o ambiente, maiores são as chances de compra. As ofertas e promoções desempenham outro grande fator, "Muitos clientes querem aproveitar os preços especiais e não resistem a uma boa promoção" (PARENTE, 2002, p. 129).

O consumidor precisa ser persuadido a acreditar que certo varejista oferece uma melhor relação de custo/benefício que os 
demais concorrentes. $\mathrm{O}$ mix promocional, portanto, é um processo de comunicação entre varejistas e consumidor, com a finalidade não só de ser informativo (fornecendo dados sobre a loja e os produtos e serviços oferecidos), mas também persuasivo (influenciando as percepções, atitudes e comportamentos do consumidor) (PARENTE, 2000, p. 242).

No "Shopping Popular" encontram-se diversas formas de comunicação mercadológica. O consumidor é instigado à compra no momento que entra no estabelecimento, pois os vendedores sempre perguntam o que o indivíduo está precisando ou procurando, usando a célebre frase "posso te ajudar $\mathrm{Sr} .{ }^{\circ} / \mathrm{Sr} .{ }^{\underline{a}}$ ".

A promoção de venda é um dos fatores mais fortes, como cita Parente (2000, p.242):

Promoção de venda é a ferramenta de comunicação impessoal, direta ou indireta, envolvendo o uso de mídia ou marketing sem mídia que oferece um valor extra ao consumidor. As formas mais comuns de promoção de venda no varejo são: prêmios, programas de fidelização e de comprador frequente, cupons, displays, demonstrações de produtos e amostras.

No Shopping Popular prevalecem os elementos visuais para a captação da atenção do cliente, além disso, os consumidores em algumas lojas recebem um cupom de desconto para próxima compra ou estará concorrendo a um brinde de sorteio. Ademais, os clientes podem ver demonstrações de produtos antes de adquirilos. É bastante possível deparar-se com divulgações em panfletos e alguns cartazes de promoção espalhados no local, a fim de atrair a atenção dos consumidores.

Ao analisar o papel da publicidade, podese descrever com toda a nitidez, que sua finalidade ativa é a persuasão. Além de trabalhar o consumo imediato, ela cria demandas futuras para salientar o dispêndio.

A propaganda não é uma arte nem uma ciência (...). Ela é uma técnica, manipulativa (...). Seu propósito essencial, capital, não é interpretar, explicar ou dignificar mas persuadir, manipular. Mas aí vai a distância entre a propaganda profissional, exercida dentro das normas éticas e a picaretagem, que por sinal só funciona a curtíssimo prazo. (BARRETO apud. ROCHA, 1995)

A publicidade traz consigo a ideia de persuasão, ela instiga o consumidor a desejar novos hábitos, além disso, o veículo de comunicação tenta seduzir e influenciar o público-alvo a adquirir tais bens/produtos sem a necessidade de tê-los, o que leva o indivíduo ao consumismo.

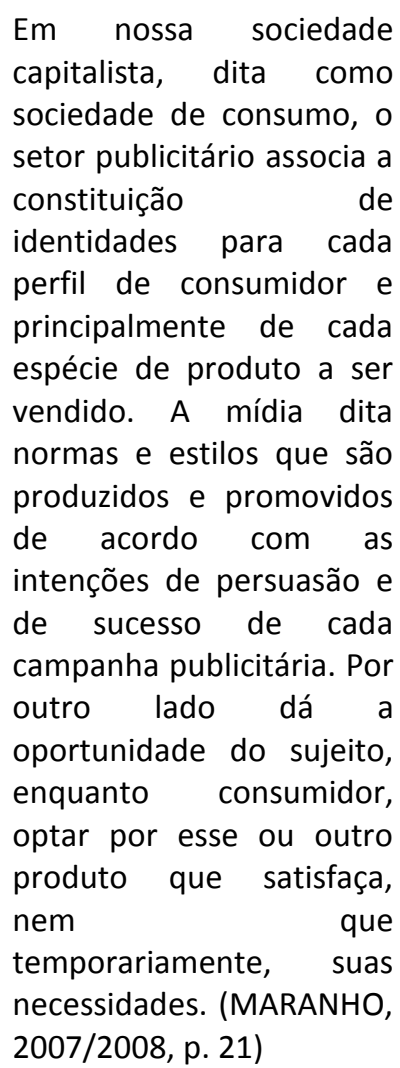

A publicidade na verdade constitui-se em uma oposição entre a produção e o consumo, humanizando o produto e dando independência a todo processo capitalista. Todos os dias surgem coisas novas no mercado e o consumidor é visto 
como um ser que faz uso da razão, dos sentidos e principalmente das emoções, na qual carrega valores simbólicos que argumentam seus atos em relação ao consumismo. O consumidor deve ser engajado, atraído, persuadido, pois quanto mais alerta ele receber, mais chance de consumir.

Barbosa (2010, p.35) aponta:

A cultura do consumo representa a importância crescente da cultura no exercício do poder. 0 poder de escola do individuo na esfera do consumo nas sociedades pós-tradicionais tem sido campo de debate sobre sua real liberdade escolar ou submissão a interesses econômicos maiores que se escondem por trás do marketing e da propaganda. Será o consumo uma arena de liberdade e escola ou de manipulação e indução? Ele é súdito ou soberano, ativo ou passivo, criativo ou determinado?

Outra ferramenta mercadológica bastante utilizada no mercado são as técnicas do Neuromarketing ${ }^{5}$, um estudo do comportamento do consumidor através da neurociência'. Lindstrom (2009) define que: "O Neuromarketing é a chave para abrir o que chamo de nossa 'lógica do consumo' - os pensamentos, sentimentos e desejos subconscientes que impulsionam as decisões de compra que tomamos em todos os dias de nossas vidas". (LINDSTROM, 2009, p. 13).

O Neuromarketing trás consigo um conjunto de recursos de enorme valor para investigar o mercado, segmentá-lo e desenvolver estratégias com êxito para produtos (imagem, marca, embalagens),

\footnotetext{
${ }^{5}$ Neuromarketing é a mistura entre neurociência e marketing que tem como principal objetivo entender o que faz um consumidor preferir uma marca, comprar ou não um produto e até mesmo se tornar um cliente fiel. Disponível em: <https://viverdeblog.com/neuromarketing/> Acessado dia 23.Dez.2019

${ }^{6}$ Neurociência é a área que se ocupa em estudar o sistema nervoso, visando desvendar seu funcionamento, estrutura, desenvolvimento e eventuais alterações que sofra. Disponível em:

< https://www.ibccoaching.com.br/portal/coaching-e-psicologia/oque-e-neurociencia/>. Acessado em: 23. Dez. 2019.
}

posicionamento, preços, comunicações e canais. Estes recursos se baseiam no conhecimento dos processos cerebrais vinculados a percepção sensorial, ao processamento da informação, a memória, a emoção, a atenção, a aprendizagem, a racionalidade e aos mecanismos que interagem com a aprendizagem e a tomada de decisões do cliente (BRAIDOT, 2000, p.16, apud RIBEIRO, 2014, p.7)

O principal objetivo do Neuromarketing é, portanto, entender o processo de tomada de decisão dos consumidores, mediante a análise do subconsciente dos mesmos. Por meio disso e das consequentes contribuições para as tradicionais áreas do marketing, os profissionais poderão atenuar o índice de produtos que fracassam no mercado, desenvolvendo produtos que satisfaçam os consumidores e gerem maior receita para as empresas (LINDSTROM, 2009, p.14).

"Examinar o comportamento humano através do entendimento do processamento de informações pelo cérebro. É somente a partir dos dados obtidos que são criadas estratégias e táticas mais eficientes para conduzir o lead pelo funil de vendas". (CARVALHO, 2017)

A metodologia utilizada para alcançar resultados que aprimorem os produtos/serviços oferecidos pelo mercado, focalizados na recepção dos clientes e na reação deles aos estímulos, analisa três áreas fundamentais do cérebro humano, são elas: 
Quadro 1. Ciência e Marketing Aliados

\begin{tabular}{|c|l|}
\hline $\begin{array}{c}\text { CÉREBRO } \\
\text { REPTILIANO: }\end{array}$ & $\begin{array}{l}\text { Controla tudo aquilo que é } \\
\text { responsável pela sobrevivência, } \\
\text { como respiração e batimentos } \\
\text { cardíacos. Ativa emoções } \\
\text { primitivas como medo, desejos, } \\
\text { fome e raiva. }\end{array}$ \\
\hline $\begin{array}{l}\text { CÉREBRO } \\
\text { LÍMBICO: }\end{array}$ & $\begin{array}{l}\text { Processa emoções mais } \\
\text { complexas. É responsável por } \\
\text { armazenar dados e é ativado por } \\
\text { sensações envolvendo os 5 } \\
\text { sentidos (olfato, paladar, audição, } \\
\text { visão e tato). }\end{array}$ \\
\hline NEOCÓRTEX: & $\begin{array}{l}\text { Essa é a parte utilizada nas } \\
\text { tomadas de decisão, já que é a } \\
\text { que controla o raciocínio e o lado } \\
\text { social. }\end{array}$ \\
\hline
\end{tabular}

Fonte: Elaboração do autor, a partir de CARVALO (2017)

Segundo Orso, Trevisol e Santos (2011, p.10):

O Neuromarketing não obriga as pessoas a comprarem, ele apenas estimula o ponto exato do cérebro, que é onde se sente prazer ou desejo de obtenção de certo produto. Ele então não determina em sua totalidade as escolhas dos indivíduos, ele descobre como o cérebro faz essas escolhas, e a partir disso pode-se atingir diretamente no subconsciente do consumidor, assim ele provavelmente cederá às estímulos apresentados pelo uso do Neuromarketing.

A partir do entendimento de todos os conceitos discutidos, as ferramentas mercadológicas se fazem presentes para ativar o "piloto automático" de cada indivíduo, o levando ao ato do consumo. As pessoas vivem em uma sociedade cada vez mais capitalista, buscam acumular bens para serem aceitos e inseridas na sociedade. É uma corrida em busca de padrões de vida. O consumo se torna invisível e explicá-lo se torna censurável.

\section{METODOLOGIA}

Metodologia é o conjunto de métodos ou caminhos que são percorridos na busca do conhecimento (ANDRADE, 2010, p.117). Referese, portanto, ao estudo com utilização de métodos e técnicas, um conjunto para dirigir-se a uma investigação. A busca pela coleta de dados permite que 0 pesquisador tenha um direcionamento de etapas a serem cumpridas, para que assim não se perca. Dessa maneira, é possível chegar ao resultado pretendido, não como algo aleatório, ao acaso. Coletar informações conexas ao assunto, por meio da pesquisa, é um ato basal para que a investigação seja pertinente e essencial.

Para a elaboração dessa pesquisa foi adotada a abordagem qualitativa em relação ao estudo do Shopping Popular, pois esta foi a que permitiu interpretar, refletir e compreendê-lo em sua fundura. Parte-se do princípio de que a pesquisa qualitativa é aquela que trabalha efetivamente com as informações coletadas pelo pesquisador, não havendo a necessidade de serem expressas numericamente, ou os números e as conclusões nelas baseadas representam um papel menor na análise, como aponta Goldenberg (2013, p.14):

$\mathrm{Na}$ pesquisa qualitativa a preocupação do pesquisador não é com a representatividade

numérica do grupo pesquisado, mas com o aprofundamento da compreensão de um grupo social, de uma organização, de uma instituição, de uma trajetória [...]

Desta maneira, a pesquisa se classifica como histórica, na qual é descrito o surgimento do "Camelódromo" até este se tornar o atual Shopping Popular. Segundo Marconi e Lakatos (2003, p.20), “[...] o processo enfoca quatro aspectos: investigação, registro análise $e$ interpretação de fatos ocorridos no passado, para, por meio de generalização, compreender o presente e predizer o futuro".

Ademais, a presente pesquisa classificase também como exploratória, pois visa agregar maiores informações sobre determinado assunto, proporcionando uma reflexão e o conhecimento 
quanto ao problema indicado, no intuito de trazer uma visão mais abarcante à sociedade.

Andrade (2010, p.112) aponta:

São finalidades de uma

pesquisa exploratória,

sobretudo quando

bibliográfica, proporcionar

maiores informações

sobre determinado

assunto; facilitar a

delimitação de um tema

de trabalho; definir os

objetivos ou formular as

hipóteses de uma

pesquisa ou descobrir um novo tipo de enfoque para o trabalho que se tem em mente.

O método adotado é o estudo de caso já que este permite um olhar para o objeto estudado, acoplado com o levantamento detalhado e profundo do assunto, tratando das etapas de análise e exposição de ideias. Tal método consiste no estudo profundo do objeto a ser analisado, de modo que se obtenha o máximo de conhecimento possível sobre ele, como aponta Gil (2012, p.57). Ainda segundo o autor, trata-se de um estudo empírico que investiga um fenômeno atual dentro do seu contexto de realidade, quando as fronteiras que separam um e outro não são claras. Consiste em avaliar o objeto de estudo com uma visão mais densa.

A observação direta intensiva, é realizada através das técnicas de observação e entrevista e proporciona uma análise da aquisição dos aspectos da realidade.

A observação é uma técnica de coleta de dados para conseguir informações e utiliza os sentidos na observação de determinados aspectos da realidade. Não consiste apenas em ver ou ouvir, mas também em examinar fatos ou fenômenos que se desejam estudar. A observação ajuda o pesquisador a identificar e a obter provas a respeito de objetos sobre os quais os indivíduos não têm consciência, mas que orientam seu comportamento.

Desempenha papel importante nos processos observacionais, no contexto da descoberta, e obriga o investigador a um contato mais direto com a realidade. É um ponto de partida da investigação social (MARCONI; LAKATOS, 2003, p. 190191).

Para a aplicação do método é necessário estar atento a algumas condições quanto à maneira como devem ser feitas às observações e registros, como apresentar os resultados e a colocação correta da observação do ponto de vista ético.

A análise dos dados, ao final da pesquisa, mostrou, essencialmente, que a sociedade de consumo transformou o principio do prazer, para o princípio da realidade. $O$ consumo cresce acelerado, causando um confronto com a sociedade, principalmente com o próprio comportamento de querer, desejar e ter. O consumismo é a circulação de capitais e a forma de garantir lucro e crescimento econômico para a sociedade, seu desenvolvimento é cada vez mais constante. Desse modo, faz-se necessário uma alta avaliação de cada individuo, sobre a diferença entre consumir o que realmente é para as suas necessidades básicas e o consumismo, que significa comprar aquilo que não precisa para satisfazer os desejos que a sociedade impõe.

\section{RESULTADOS}

As coletas dos dados apresentados delinearam o estudo de caso do Shopping Popular, constituídas por meio de análise documental e observação direta intensiva. Foram feitas visitas as local, durante quinze (15) dias e realizados diários de bordo, com anotações do que foi observado no decorrer das visitas. A análise da informação se faz presente, nesta pesquisa, mediante ao cruzamento das informações obtidas e interpretadas, com base na fundamentação teórica.

As observações foram realizadas com o objetivo de detectar os elementos mercadológicos no Shopping Popular e a relação destes com os consumidores do local. As visitas ao espaço permitiram a análise das ferramentas mercadológicas utilizadas no ambiente, às técnicas de venda, promoção, ambientação, identidade visual de cada uma das lojas. 
Em entrevista com Rafaela Fernandes Kemmer $^{7}$, gerente da administração do Shopping Popular, localizado atualmente na Rua Sergipe, no Centro da cidade, foi possível auferir que atualmente o recinto conta com 356 lojas e uma média de 1.000 pessoas trabalhando no local. 0 horário de funcionamento é de segunda a sexta, das $09 \mathrm{~h}$ às $18 \mathrm{~h}$. O horário de maior movimento é em torno do $12 \mathrm{~h} 00$ às $13 \mathrm{~h} 30 \mathrm{em}$ que se se estima a circulação de 9.000 pessoas que gastam um tempo considerado de 15 a 45 minutos.

As cores são distintas, mas a que predomina no prédio é o tom vermelho, com escritas em preto. Um prédio antigo, mas que está em constantes reformas e adequações, para atender todo o público. Possuem escadas rolantes, a iluminação do ambiente é composta por diversas lâmpadas espalhadas pelos corredores e iluminação individual de cada loja, cada uma com as suas particularidades, além da maior parte do chão ser de cerâmica. Todos os ambientes têm sistema de segurança, com alarmes e câmeras. Além de uma equipe de manutenção de obras e limpezas espalhadas nos corredores.

Existem lojas de todos os tipos, como: decorações, roupas, sapatos, artesões, brinquedos, infantil, eletrônicos, eletrodomésticos, games, bijuterias, semijoias, decorações para casa, cama, mesa e banho, CDs e DVDs, bebidas, ervas medicinais, artigos esportivos, perfumes, maquiagem, ferramentas, informatica, bonés, bolsas, acessórios, artigos religiosos, tabacaria, artigo para carro e pesca, entre outros.

A sonorização do local é executada com a presença de aparelhos de som, cada loja com a sua peculiaridade e estilo musical. Existe uma grande comunicação em massa, com vozes, sons e ruídos. Sua identidade é a de um local bem movimentado, passando para o público a sensação de dia a dia, ânimo, povão e estímulo da vontade de comprar.

Determinadas lojas contém banners com campanhas de promoção, logotipo, e fotos dos produtos que são comercializados. As vitrines são bem iluminadas, com os produtos em amostra. A forma de pagamento predominante é a vista ou cartão de crédito ou débito. Todas as lojas mantém um padrão, com bastante reposição de estoque. É possível encontrar alguns displays

\footnotetext{
${ }^{7}$ Entrevista com Rafaela Fernandes Kemmer, Gerente Administrativa do Shopping Popular, realizada dia 05.Dez.2019
}

pelas lojas como forma de decoração e frases que caracterizam o olhar do consumidor, do tipo: "É só hoje, toda loja em promoção"; " $50 \%$ de desconto na compra do 2 eletrônico"; "Compra um e leve dois", entre outras. Blessa (2006) examinou que $85 \%$ das obtenções de produtos são definidas no interior da loja, influenciada por fatores atinentes à atmosfera de compra, no ponto de venda.

Blessa (2006, p. 49) aponta que "Depois da visão, que nos apresenta ao vivo os produtos, o olfato é o sentido que mais provoca emoções. Um perfume ou cheiro dá personalidade ao ambiente, e provocam lembranças, desejos e sentimento de fome, saudade, desagrado e até felicidade". Esses elementos mostram abertamente o que Shimp (2002) pondera como comunicação mercadológica: produtos alocados em pontos estratégicos, com o desígnio de influenciar a compra e o consumismo.

\section{Uma Análise Da Historia Do "Camelódromo"}

Quando se pensa em "Camelódromo", logo vem à mente a ideia de comércio popular, com diversos vendedores ambulantes concentrados em um só espaço, vendendo mercadorias a preços baixos. Além disso, nesses espaços há a possibilidade de encontrar diversas promoções, produtos diversificados, muito movimento, réplicas de mercadorias originais, sendo essas importadas de maneira legalizada ou não.

Em 1990, a Prefeitura de Londrina-PR, na época sob a administração do Luiz Eduardo Cheida, instituiu determinadas opções de planejamento para deslocar os vendedores ambulantes das ruas para um espaço físico específico, reservado à comercialização de suas mercadorias, pois os mesmos se concentravam nas calçadas, cruzamentos, praças e ruas da região central da cidade. Eram montadas barracas provisórias que não ofereciam qualquer condição de trabalho. Criou-se então a necessidade de restituir a atividade em um lugar apropriado, para assim evitar uma sequência de problemas como o uso do espaço público na área central, reclamações de lojistas e em relação à urbanização, pois o comércio de rua atrapalhava a livre circulação de passantes.

Segundo Oliveira (2009, p.147), inaugurase o "Camelódromo" em 1996, localizado no interior do museu histórico de Londrina Padre 
Carlos Weiss, que por sua vez se encontra nas calçadas da Avenida Leste-Oeste. O propósito da inauguração consistiu na retirada dos ambulantes das ruas e no restabelecimento da atividade para um comércio formal, já que na época, o desemprego era acentuado. Começa uma jornada de conflitos com o Ministério Público e a Policia Federal, motivados pelo fato de muitas mercadorias, que cruzam a fronteira do Paraguai, não possuírem notas fiscais.

O comércio popular tomou uma grande proporção, tanto que foi necessário repensar o local onde os camelôs estavam trabalhando. Nos anos 2000, a prefeitura, o representante dos camelôs, o presidente da Associação dos Vereadores de Produtos Nacionais e Importados (AVPNI) e a Companhia Municipal de Transito e Urbanismo (CMTU), estabeleceram uma nova proposta que consistia em um novo projeto para - "Camelódromo". Foram muitas ideias, vários planejamentos, debates, pesquisas, visitas e contato com outras prefeituras que estavam na mesma situação, para testificar o futuro dos camelôs.

Conforme Oliveira (2009, p. 149-150) aponta:

Nos meados de 2001, um segundo agrupamento de camelôs, ainda maior que o do primeiro Camelódromo, passou a funcionar no referido trecho da rua São Paulo, reunindo 220 camelôs em barracas de $1.5 \mathrm{~m}$ de largura. Essa nova concentração constituiu o segundo local de origem da grande maioria dos camelôs que foram para o novo Camelódromo de Londrina, na esquina das Ruas Mato Grosso e Sergipe.

O prefeito da época era Nedson Michheleti. Sua missão era organizar a urbanização da cidade e fazer com que os camelôs tivessem um local fixo. Foi criada uma serie de parâmetros com regras e deveres que, dentre outras coisas, incluíram: a definição do espaço, direitos da prefeitura e dos associados, contratos de alugueis, medições do espaço, duração de tempo específica, empreendimentos, tipos de mercadorias a comercializar, taxas, entre outros.

O poder público propôs, então, alugar um prédio no centro da cidade $\mathrm{e}$ implementar as reformas necessárias para acomodar os 316 camelôs. Em janeiro de 2003 o Shopping Popular foi inaugurado com 316 boxes medindo $4 \mathrm{~m} 2$ de área em formato de $2 \mathrm{~m}$ por $2 \mathrm{~m}$. Houve investimentos públicos na ordem de R\$ $1.500 .000,00$ com as reformas e com a locação até 2004. "Não chove dentro!" Esta era a maior vantagem do novo local, segundo os próprios camelôs, além da localização. (AVANZI, 2006, p.52).

A inauguração do Shopping Popular não só realocou os camelôs organizados em associações, como também os incluiu numa sociedade com normas trabalhistas e os fez vendedores com direitos e deveres.

De modo geral, o comércio praticado no Shopping Popular consiste em uma atividade que reúne uma porção de aspectos particulares, com grande movimentação econômica para a cidade, influência e técnicas de venda. Historicamente, desempenha múltiplos papéis na sociedade e é responsável pelo sustento de mais de 353 famílias, sendo alocados mais de 1.000 trabalhadores. 
Figura 1. Camelódromo de Londrina

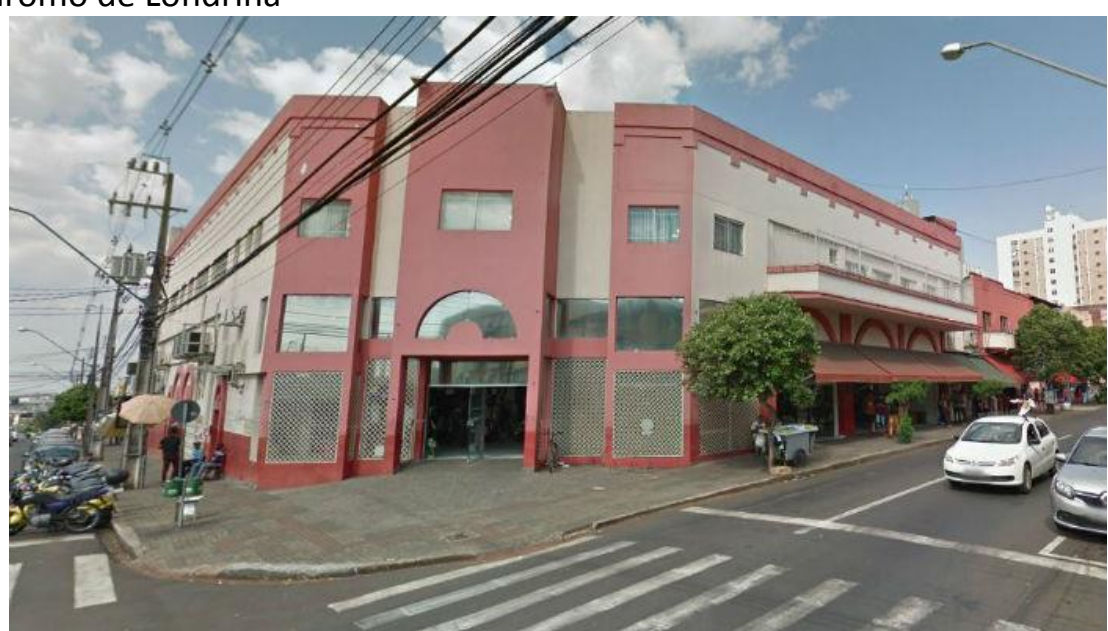

Fonte: Jornal Bonde. Disponível em: < https://www.bonde.com.br/img/bondenews/2019/07/img_1_3_105.jpg>.

Acesso em: 25 de Novembro de 2019

\section{DISCUSSÃO}

Com base nos fundamentos aprendidos na parte teórica deste trabalho e nos dados coletados pelo estudo, foi possível analisar os impactos do consumo na sociedade contemporânea, colocada como objetivo geral deste trabalho. $O$ estudo possibilitou 0 entendimento de uma sociedade de produção, para uma sociedade consumista.

Houve uma passagem da sociedade de produção para a sociedade do consumo. 0 capitalismo é o fator principal, baseado em fins lucrativos. $O$ excesso de produção mundializado, contribuiu para a facilidade em adquirir créditos para suprir toda oferta e demanda. 0 desenvolvimento estratégico de vendas, marketing e publicidade se fizeram extremamente necessários para atrair os consumidores, visando um sistema financeiro voltado totalmente para o crescimento da sociedade de consumo.

De acordo com o estudo ${ }^{9}$ do Serviço de Proteção ao Crédito (SPC Brasil) e pela Confederação Nacional de Dirigentes Lojistas (CNDL) 44,5\% dos entrevistados não resistem aos desejos, pois afirmam que podem desperdiçar uma oportunidade ou até mesmo uma promoção, compras imediatistas e impulsivas, sem haver necessidade por parte dos

\footnotetext{
${ }^{9}$ A pesquisa foi realizada pelo Serviço de Proteção ao Crédito (SPC Brasil) e pela Confederação Nacional de Dirigentes Lojistas (CNDL) com 745 consumidores acima de 18 anos nas 27 capitais e procurou compreender o papel das emoções no comportamento das compras impulsivas. A margem de erro é de 3,5 pontos percentuais com uma margem de confiança de 95\%. Disponível em: https://www.spcbrasil.org.br/pesquisas/pesquisa/1207 Publicado dia 13.Jan.2018.
}

consumidores. "E O resultado desse comportamento não poderia ser outro: muitos acabam ficando com o orçamento mais apertado. Segundo a pesquisa, 30,8\% dos consumidores reconhecem que estão com as finanças pessoais descontroladas por causa de compras impulsivas" (SPC BRASIL, 2018).

É preciso dizer que a sociedade moderna é impulsionada pelos desejos, pela alienação provocada pelo que é apresentado e imposto nos veículos de comunicação, induzida pelo mercado econômico. O consumo é uma constante busca de experiências, status, moda, glamour e valores sociais. O prazer por consumir é continuo, o "ter" se torna mais formidável do que o "ser", uma prática articulada pelos produtos e mercadorias que são oferecidas pelos lojistas. Os consumidores têm em mente que são influenciados a todo o momento. Seja no trabalho, escola, faculdade, academia, aonde estiver sempre terá um individuo para compartilhar algo que adquiriu de novo e que está na moda.

Há na sociedade uma constante busca pela ilusória procura da satisfação das necessidades, criadas pelo mercado capitalista, que deflagram no ato do consumo desregrado, motivado pelo desejo de reconhecimento social e a busca do bem-estar. São usadas frases do tipo: "eu mereço", "trabalho duro, eu preciso", "é só uma blusinha", "todo mundo está usando", "podemos dividir no cartão", entre outras frases conhecidas.

Diante das análises realizadas neste estudo de caso e dos resultados obtidos na pesquisa, faz-se necessário uma alta reflexão 
sobre equilibrar a orgia consumista e sistematizar a sociedade em massa, procurando levantar os seguintes questionamentos a todo instante: Porque alcançar ou querer tudo o que é imposto? Porque exijo me encaixar dentro dos padrões da sociedade? Porque ter uma vida de consumo com bens supérfluos e inúteis?

Este artigo confirma a importância do olhar critico sobre a natureza do consumo e seus impactos na vida do individuo. Assim como os meios mercadológicos utilizados para chamar atenção dos consumidores. É preciso fazer uma seleção das informações que recebemos, pois quanto mais os indivíduos são bombardeados, menos chances eles tem de selecionar, pensar e raciocinar sobre o ato do consumismo. Contudo, o único momento em que as pessoas se encontram fora do sistema econômico do consumo é quando estão dormindo.

\section{REFERÊNCIAS}

ANDRADE, M. M. Introdução à metodologia do trabalho científico. 10. ed. São Paulo: Atlas, 2010.

AVANZI, J. O Potencial empreendedor dos microempresários do shopping popular de Londrina. 2006. Dissertação (Mestrado em Administração) - Universidade Estadual de Londrina, Londrina, 2006.

BARBOSA, L. Sociedade de consumo. 3.ed. Rio de Janeiro: Jorge Zahar, 2010.

BAUDRILLARD, J. A sociedade de Consumo. Lisboa: Edições 70, 1981.

BAUDRILLARD, J. A sociedade de consumo. Tradução de Arthur Morão. Lisboa: Edições 70, 2007.

BAUMAN, Z. Vida para consumo: a transformação das pessoas em mercadoria. Tradução de Carlos Alberto Medeiros. Rio de Janeiro: J. Zahar, 2008.

BLESSA, R. Merchandising no ponto de venda. 4.ed. São Paulo: Atlas, 2006.

BOCCATO, V. R. C. Metodologia da pesquisa bibliográfica na área odontológica e o artigo científico como forma de comunicação. Odontol. Universidade de São Paulo, São Paulo, v. 18, n. 3, p. 265-274 f. set./dez., 2006.
BULGARELLI,Waldirio. A revolução Industrial 1780-1880. São Paulo: Pioneira, 1975.

CARVALHO, H. Ciência e Marketing aliados: o que o Neuromarketing pode ensinar sobre a mente dos consumidores para erar mais vendas. Viverdeblog, 03 out. de 2017. Disponível em: https://viverdeblog.com/neuromarketing/.

Acesso em: 23 dez. 2019.

GIL, A. C. Métodos e técnicas de pesquisa social. 6. ed. São Paulo:. Atlas, 2012

GOLDENBERG, M. A arte de pesquisar. 13. ed. Rio de Janeiro: Record, 2013.

KUNSCH, M. Planejamento de relações públicas na comunicação integrada. São Paulo: Sammuns, 2003.

LAKATOS, E. M.; MARCONI, M. A. Técnicas de Pesquisa. 5. ed. São Paulo: Atlas, 2002.

LAKATOS, E. M.; MARCONI, M. A. Fundamentos de metodologia científica. 5. ed. - São Paulo: Atlas, 2003.

LINDSTROM, M. A lógica do consumo: verdades e mentiras sobre por que compramos. Rio de Janeiro: Nova Fronteira, 2009.

MARANHO, G. A publicidade e o consumo. Maringá: Programa de Desenvolvimento Educacional: Fundação Universidade Estadual de Maringá, 2007/2008.

OLIVEIRA, E. Divisão do trabalho e Circuitos da Economia Urbana em Londrina - PR. 2009. Tese (Doutorado em Geografia Humana) Universidade de São Paulo. São Paulo, 2009.

ORSO, N. L.; TREVISOL, M. G. SANTOS, S. S. S. O Neuromarketing e suas aplicações no campo da comunicação publicitária. Iniciacom, São Paulo, v. 3, n. 2. p.1-14, 2011.

PARENTE, J. Varejo no Brasil: gestão e estratégia. São Paulo: Atlas, 2000.

RIBEIRO, B. L. Uma análise do Neuromarketing pela perspectiva de especialistas. In:SIMPÓSIO DE EXCELÊNCIA EM ESTÕ E TECNOLOGIA. 11., 2011, Rio de Janeiro. Anais [...]. Rio de Janeiro, 2011. 
RIBEIRO, G. S. A influência do camelódromo de Londrina sobre o comércio formal de seu entorno. 2010. Dissertação (Mestrado em Geografia, Meio Ambiente e Desenvolvimento) Universidade Estadual de Londrina, Londrina, 2010.

RIOUX, J-P. A revolução industrial: 1780-1880. São Paulo: Pioneira, 1975.

ROCHA, E. A sociedade do sonho: comunicação, cultura e consumo. Rio de Janeiro: Mauá Editora, 1995.

TORQUATO, G. Estratégias de comunicação nas empresas modernas. In: CONGRESSO BRASILEIRO DE COMUNICAÇÃO EMPRESARIAL.3., 1985, São Paulo. Anais [...]. São Paulo: Aberje, 1985. Mímeo. Apud KUNSCH, 2003.

SHIMP, T. A. Propaganda e promoção: aspectos complementares da comunicação integrada de marketing. Tradução de Luciana de Oliveira Rocha. Porto Alegre: Bookman, 2002.

SPC BRASIL. $36 \%$ dos consumidores fazem compras para aliviar o estresse, aponta pesquisa do SPC Brasil. São Paulo, 13 Jan. 2018. Disponível em:

https://www.spcbrasil.org.br/pesquisas/pesquisa /1207. Acesso em: 12 dez. 2019. 